Article type : Original Research

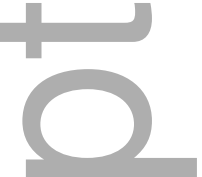

The Impact of an Integrated Diabetes Service involving Specialist

Outreach and Primary Healthcare on Risk Factors for Micro and

Macrovascular Complications in Diabetes in Remote Indigenous

\title{
Communities in Australia
}

\section{Objective}

To determine the impact of an integrated diabetes service involving specialist outreach and primary healthcare teams on risk factors for micro and macrovascular complications in diabetes in three remote Indigenous Australian communities over a 12-month period.

\section{Design}

Quantitative, retrospective evaluation.

\section{Setting}

Primary healthcare clinics in remote Indigenous communities in Australia.

\section{Participants}

124 adults (including 123 Indigenous Australians) (76.6\% females) with diabetes living in remote communities.

\section{Main outcome measures}

Glycosylated haemoglobin, lipid profile, estimated glomerular filtration rate, urinary albumin:creatinine ratio, and blood pressure.

\section{Results}

This is the author manuscript accepted for publication and has undergone full peer review but has not been through the copyediting, typesetting, pagination and proofreading process, which may lead to differences between this version and the Version of Record. Please cite this article as doi: 10.1111/ajr.12426

This article is protected by copyright. All rights reserved 
Diabetes prevalence in the three communities was high at $32.8 \% .124$ patients reviewed by the outreach service had a median consultation rate of 1.0 by an endocrinologist and 0.9 by a diabetes nurse educator over the 12-month period. Diabetes care plans were made in collaboration with local primary healthcare services, which also provided patients with diabetes care between outreach team visits. A significant reduction was seen in median (IQR) glycosylated haemoglobin from baseline to 12 months $(89 \mathrm{mmol} / \mathrm{mol}$ (65-105) vs. $81 \mathrm{mmol} / \mathrm{mol}(60-99), p=0.002)$. Median (IQR) total cholesterol was also reduced $(4.4 \mathrm{mmol} / \mathrm{l}(3.6-5.0)$ vs. $4.0 \mathrm{mmol} / \mathrm{l}(3.5-4.5), p=0.038)$. The number of patients prescribed glucagon-like peptide-1 analogues and dipeptidyl peptidase-4 inhibitors increased over the 12 months, and an increase in the number of patients prescribed insulin trended towards statistical significance.

\section{Conclusion}

A collaborative healthcare approach to deliver diabetes care to remote Indigenous Australian communities was associated with an improvement in glycosylated haemoglobin and total cholesterol, both important risk factors respectively for micro and macrovascular complications in diabetes.

\section{Key Words}

Indigenous Health, Diabetes Care, Remote Outreach

\section{What is already known on this subject?}

- The prevalence of diabetes and its associated complications are disproportionately higher in Indigenous Australians compared to nonIndigenous Australians.

- People who live in remote communities encounter multiple barriers to accessing specialist healthcare.

\section{What does this study add?}


- Diabetes prevalence rates in remote Indigenous communities are higher than rates previously described in the remote Indigenous populations in Australia.

- Integrated diabetes care involving specialist outreach and primary healthcare in a remote Indigenous community setting was associated with an improvement in important risk factors for micro and macrovascular complications in diabetes.

\section{Introduction}

Diabetes is having a considerable impact on the health and wellbeing of Indigenous Australians, who experience high prevalence rates of diabetes, at more than twice the rate of the general population in Australia (5.1\% vs 11.1\%). ${ }^{1}$ Moreover, Indigenous Australians living in remote areas are twice as likely to have diabetes compared to Indigenous Australians living in nonremote areas (20.8\% versus $9.4 \%)^{1}$ Indigenous Australians are overrepresented in the prevalence of diabetes complications, ${ }^{2}$ and mortality rates secondary to diabetes are also disproportionately high compared to nonIndigenous Australians. ${ }^{3}$ Given the existing health disparities and high burden of disease, there is a clear need for effective diabetes care in remote Indigenous communities that will lead to improved health outcomes. However, the practicalities of providing specialist diabetes care to these communities are fraught with challenges. Multiple barriers to care exist, including environmental and infrastructural barriers such as geographical remoteness, poor road access and lack of public transport to the nearest regional centres, socio-economic barriers including food insecurity, and the existence of culturally-inappropriate health service structures. ${ }^{4-6}$

In 2011, a specialist diabetes outreach service comprising a team of diabetes nurse educators (DNE) and endocrinologists was established to support 
remote primary healthcare services to deliver diabetes care to eleven remote Indigenous communities, all located within one state of Australia. Prior to this, diabetes care was primarily delivered by local primary healthcare services.

Each community clinic was visited three to four times per year by an outreach DNE, and twice yearly by an endocrinologist. The majority of patients with diabetes who were reviewed by the outreach team were referred by the local primary healthcare team or identified through regional primary healthcare information systems. A priority status was assigned to patients to enable the healthcare teams to identify and prioritise delivery of care to patients with poorly controlled diabetes and those with diabetes complications (see Table 1).

At each visit, patients were reviewed, and then the outreach team provided clinical advice including diabetes treatment recommendations to the patients, the remote medical practitioners, Aboriginal health workers, and remote area nurses, and care plans were formulated collaboratively between both services. Clinical practice was aligned with existing remote primary healthcare guidelines ${ }^{7}$ and care plans were implemented by the primary healthcare team, who provided patients with diabetes care between specialist outreach visits. Education and up-skilling in diabetes care were frequently provided by the outreach team to primary healthcare staff during the outreach visits, and the latter received clinical support from the outreach team between visits.

A quantitative, retrospective evaluation was undertaken to determine the prevalence of diabetes in remote Indigenous communities, and to determine the impact of this integrated model of care on diabetes outcomes over a 12month period, specifically looking at cardiovascular and renal risk factors including glycosylated haemoglobin (HbA1c), lipid profile, blood pressure (BP), 
estimated glomerular filtration rate (eGFR) and urinary albumin:creatinine ratio (ACR).

Methods The evaluation was conducted in three remote community-based primary healthcare services whose patients were recipients of the integrated diabetes service. The communities were situated between 100-300 kilometers by road from the closest regional centre. The estimated prevalence of diabetes in the adult population within each community was calculated from regional primary healthcare information systems and Australian census data. ${ }^{8}$ The adult ( $\geq 15$ years of age) population size in each community was 104,148 and 489 persons respectively. ${ }^{8}$

The total number of patients with diabetes seen by the outreach team and frequency of consultations for each patient was determined. All adult patients with diabetes who had received a least one face-to-face clinical consultation with the outreach team between April 2011 and May 2014 were included in the initial analysis to determine access rates to the outreach service. Patients who were reviewed by the outreach team for less than 12 months, or who were not assigned a priority status (see Table 1) were excluded from the analysis relating to clinical parameters and medications.

Clinical data was extracted from patient records through regional primary healthcare information systems. Data was collected at baseline (at the time of first consultation with the outreach service), and at 12 months (+/- 3 months) after the initial review. Data included parameters associated with the risk of micro and macrovascular complications, including renal and cardiovascular disease. These included $\mathrm{HbA1c}$, total cholesterol, triglycerides, high density lipoprotein cholesterol (HDL-C), low density lipoprotein cholesterol (LDL-C), eGFR, urinary ACR, and systolic and diastolic BP (SBP and DBP). The eGFR was ready-formulated by the clinical information systems accessed, and was 
reported as ' $>60 \mathrm{ml} / \mathrm{min} / 1.73 \mathrm{~m}^{2}$ if a patient's eGFR was above this level. Prescribed medications were reviewed at baseline and 12 months.

Univariate descriptive analysis of data collected was undertaken and reported as medians and interquartile ranges (IQR) or proportions with $95 \%$ confidence intervals (Cl). Bivariate proportions were compared using the Chi-square test. Changes in clinical markers over time were analysed using non-parametric repeated measures analysis (Wilcoxon signed-rank test). Statistical analysis was undertaken using SPSS (v17.0 for Windows; SPSS, Chicago, IL, USA) and Intercooled Stata 9.2 (Stata Corporation, College Station, TX, USA). All tests were two-tailed and a $p$-value of $<0.05$ was taken to represent statistical significance.

Approval was obtained from stakeholders and representatives from each community to conduct the study. Ethics approval was granted by the regional Human Research Ethics Committee (HREC 13-153).

\section{Results}

The average prevalence of known diabetes for all three communities was elevated compared to the estimated rate in the remote Indigenous population in Australia ( $32.8 \%$ vs $20.8 \%{ }^{1}$ ) (see Table 2 ). There was a significant difference in the prevalence of known diabetes between the communities $(p<0.001)$, the highest rate being $59.6 \%$ in Community B (see Table 2). There was also a difference in the proportion of adults with diabetes reviewed by the service $(p<0.001)$, with a greater proportion of patients seen in Community B (see Table 2). 153 adults were reviewed at least once by the specialist diabetes outreach team during the study period.

124 of the 153 patients accessed the outreach service for $\geq 12$ months and were assigned a priority status (see Table 1). Priority 1 status was given to $52.4 \%$ of patients, priority 2 status to $24.2 \%$ and priority 3 status to $23.4 \%$ 
respectively. Demographic and baseline data for the 124 patients are outlined in Table 3. All but one of the patients were Indigenous Australians. The majority of patients who accessed the outreach service were women. A significant difference was seen in $\mathrm{HbA1c}(p=0.010), \mathrm{HDL}-\mathrm{C}$ levels $(p=0.006)$ and triglyceride levels $(p=0.008)$ between the three communities at baseline.

Other baseline parameters were similar between each community.

For the 124 patients, over the total period of review there were 243 face-toface consultations by an endocrinologist (the majority in partnership with a DNE) and 298 consultations by a DNE alone. This corresponded to a median consultation rate of 1.0 endocrinologist consultation and 0.9 DNE consultations per patient per year.

By 12 months, $63 \%$ of patients had a reduction in $\mathrm{HbA} 1 \mathrm{c}$. A significant difference in $\mathrm{HbA} 1 \mathrm{c}$ was seen between baseline and 12 months (median (IQR) (HbA1c 89mmol/mol [65-105] vs. 81 mmol/mol [60-99], $p=0.002)$.

A significant difference in total cholesterol level was seen between baseline and 12 months (median [IQR] total cholesterol 4.4mmol/I [3.6-5.0] vs. 4.0mmol// [3.5-4.5], $p=0.038)$. No differences were seen in LDL-C, HDL-C, triglyceride levels, BP, or urinary ACR levels over the 12-month period (see Table 4). Diabetes medication regimens were optimised following the commencement of the outreach service, and a significant increase in the number of patients prescribed glucagon-like peptide-1 (GLP-1) analogues $(p=0.007)$ and dipeptidyl peptidase-4 (DPP4) inhibitors $(p=0.004)$ was seen after 12 months. Insulin doses increased in $67 \%$ of patients by 12 months, and an increase in the number of patients prescribed insulin trended towards statistical significance $(p=0.05)$. No changes were seen in the number of patients prescribed antihypertensive agents or statins between baseline and 12 months.

\section{Discussion}


Medical outreach programs have been implemented throughout Australia, and have resulted in greater access to multidisciplinary health services for rural and remote areas. ${ }^{9}$ Surgical outreach services to remote Indigenous communities in Australia have been shown to improve access to specialist consultations and procedures, and have been associated with a reduced rate of procedures needing hospital admission. ${ }^{10}$ Outreach services for diabetic retinopathy screening in remote Australian communities have also been shown to improve accessibility to retinal screening and reduce the risk of preventable blindness. ${ }^{11}$ Improved health outcomes and greater efficiency within services have been demonstrated when specialist outreach services are part of a multi-faceted intervention, involving collaboration with primary healthcare and other relevant health services. ${ }^{9,11,12}$

The purpose of the diabetes outreach service was to deliver comprehensive diabetes care to remote Indigenous communities in partnership with local primary healthcare services, where clinical decision-making and formulation of care plans were determined via a collaborative process involving both services. An improvement in glycaemic control was seen over the 12-month study period. The effect of good glycaemic control on reducing risk of microvascular complications including diabetic nephropathy in patients with type 2 diabetes is well described in the literature, ${ }^{13-15}$ highlighting the importance of finding effective models of care that enable these targets to be reached. Total cholesterol, an important risk factor for macrovascular disease ${ }^{16}$ also decreased over the study period.

Several factors may have contributed to the association demonstrated between this model of care and an improvement in glycaemic and lipid control. Outreach visits enabled patients to access specialist diabetes care within their own communities, averting the need to travel long distances to the nearest regional diabetes service. The assignment of a priority status 
enabled the healthcare teams to focus care towards patients with poorly controlled diabetes and those with diabetes complications. Also, the model of care endeavored to strengthen the capacity of the primary healthcare services to deliver effective diabetes care, through up-skilling and education in diabetes management.

The estimated diabetes prevalence rates in the three communities were elevated, and were significantly different between the communities (Community B (59.6\%) vs. A (31.1\%) and C (27.6\%)). Also, there was a lower proportion of patients reviewed by the outreach service in the largest community compared to the other two communities. We were unable to identify any specific factors that may have contributed to these differences. A number of other limitations were identified in the study. We were unable to stratify changes in results by community, as the numbers of participants at each site were too small to adequately power such an analysis, whereas pooling the data from all three sites gave greater statistical power. With regard to renal parameters, the majority of patients had an eGFR $>60 \mathrm{ml} / \mathrm{min} / 1.73 \mathrm{~m}^{2}$ at baseline and at 12 months. We were therefore unable to provide meaningful comparison of any changes occurring in eGFR over the study period so we excluded this data from the results section. The lack of a control group for comparison and the study's retrospective, observational design made it difficult to determine the level of impact that the integrated diabetes service had on diabetes outcomes. Also, the education sessions and up-skilling in diabetes care provided by the outreach team were not quantitatively measured. Finally, this study is likely to have benefited from a qualitative research component to assess patient and healthcare staff satisfaction with the integrated service.

In remote Indigenous Australian communities where the prevalence of diabetes is high, there is a critical need for accessible, community-based, and culturally acceptable models of care to improve diabetes outcomes and 
reduce the burden of chronic disease and disability. Outreach services can improve access to specialist care, and when integrated with primary healthcare, can be associated with an improvement in risk factors for micro and macrovascular complications in diabetes. The success of an integrated diabetes service for remote communities is dependent on a multitude of factors, including adequate funding and resources, a well-supported workforce, and collaborative alliance between services to ensure wellcoordinated patient care. Lastly, the cultivation of equitable partnerships between service providers and communities is crucial to ensure that communities are provided with the opportunity to help shape the way the care is delivered, to make the service useable and acceptable to its consumers.

\section{References}

1. Australian Bureau of Statistics, 2014. Australian Aboriginal \& Torres Strait Islander Health Survey: Biomedical results 2012-13, cat. no. 4727.0.55.003, ABS, Canberra.

2. Maple-Brown L, Cunningham J, Dunne K, Whitbread C, Howard D, Weeramanthri TS et al. Complications of diabetes in urban Indigenous Australians: the DRUID study. Diabetes Res Clin Pract 2008; 80: 455-62.

3. Australian Bureau of Statistics, 2015. Leading causes of Aboriginal and

Torres Strait Islander deaths. Causes of death, Australia, 2013, cat. no. 3303.0, ABS, Canberra.

4. Gruen RL, Weeramanthri TS, Baillie RS. Outreach and improved access to specialist services for Indigenous people in remote Australia: the requirements for sustainability. J Epidemiol Community Health 2002;

56: 517-21. 
5. Australian Bureau of Statistics, 2014. Australian Aboriginal \& Torres Strait Islander Health Survey: Nutrition Results - Foods and Nutrients, 2012-13, cat. no. 4727.0.55.005, ABS, Canberra.

6. Australian Bureau of Statistics, 2009. National Aboriginal \& Torres Strait Islander Social Survey 2008, cat. no. 4714.0, ABS, Canberra.

7. Central Australian Remote Practitioner's Association (CARPA) Standard Treatment Manual ( $6^{\text {th }}$ ed.) Combined checks for chronic diseases. [cited 2015 December 3]. Available from URL: http://www.remotephcmanuals.com.au/publication/stm/Combined_c hecks_for_chronic_diseases.html

8. Australian Bureau of Statistics, 2011. Census QuickStats. [cited 2015 November 12]. Available from URL:

http://www.abs.gov.au/websitedbs/censushome.nsf/home/quickstats

9. Gruen RL, Weeramanthri TS, Knight SE, Bailie RS. Specialist outreach clinics in primary care and rural hospital settings. Cochrane Database Syst Rev 2004; (1): CD003798.

10. Gruen RL, Bailie RS, Wang Z, Heard S, O’Rourke IC. Specialist outreach to isolated and disadvantaged communities: a population-based study. The Lancet 2006 ; 368: 130-8.

11. Glasson NM, Crossland LJ, Larkins SL. An innovative Australian outreach model of diabetic retinopathy screening in remote communities. $J$ Diabetes Res 2016; 2016: 1267215

12. Ballestas T, McEvoy S, Swift-Otero V, Unsworth M. A metropolitan Aboriginal podiatry and diabetes outreach clinic to ameliorate footrelated complications in Aboriginal people. ANZ J Public Health 2014;

38: $492-493$

13. UK Prospective Diabetes Study Group. Intensive blood-glucose control with sulphonylureas or insulin compared with conventional treatment 
and risk of complications in patients with type 2 diabetes (UKPDS 33). The Lancet 1998; 352: 837-53.

14. ADVANCE Collaborative Group. Intensive blood glucose control and vascular outcomes in patients with type 2 diabetes. N Engl J Med 2008; 358: 2560-72.

15. Holman RR, Paul SK, Bethel MA, Matthews DR, Neil HA. 10-year followup of intensive glucose control in type 2 diabetes. N Engl J Med 2008; 359: 1577-89.

16. Peters SA, Singhateh Y, Mackay D, Huxley RR, Woodward M. Total cholesterol as a risk factor for coronary heart disease and stroke in women compared with men: A systematic review and meta-analysis. Atherosclerosis 2016; 248:123-31.

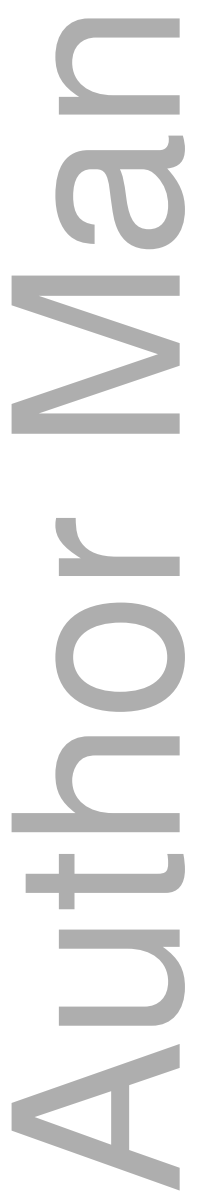


Table 1: Diabetes outreach service priority status and follow-up action plan

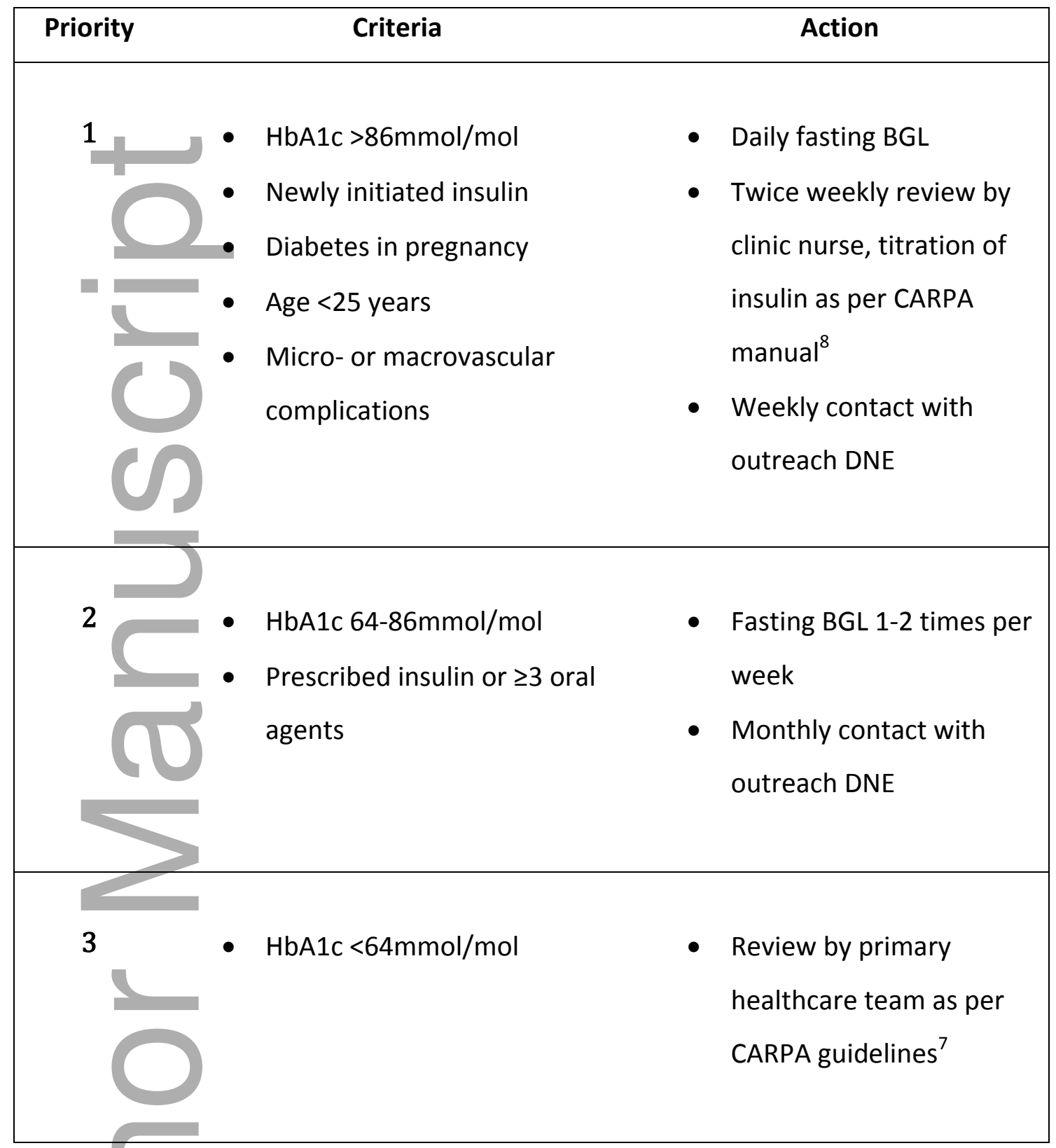

Glycosylated haemoglobin, HbA1c, blood glucose level, BGL, DNE, diabetes nurse educator, Central Australian Rural Practitioner's Association, CARPA

This article is protected by copyright. All rights reserved 
Table 2: Respective comparisons of diabetes prevalence rates and proportion of patients reviewed by the outreach service in Communities $A, B$ and $C$

\begin{tabular}{|c|c|c|c|c|c|}
\hline & & \multicolumn{3}{|c|}{ Community } & $p$-value \\
\hline 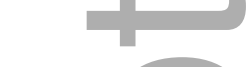 & All & A & B & C & \\
\hline $\begin{array}{c}\text { Total adult } \\
\text { population }(n)\end{array}$ & 741 & 148 & 104 & 489 & \\
\hline $\begin{array}{l}\text { Prevalence of } \\
\text { diabetes in } \\
\text { total adult } \\
\text { population } \\
(95 \% \mathrm{Cl})(n)\end{array}$ & $\begin{array}{c}32.8 \% \\
(29.5-36.3) \\
(243 / 741)\end{array}$ & $\begin{array}{c}31.1 \% \\
(24.2-38.9) \\
(46 / 148)\end{array}$ & $\begin{array}{c}59.6 \% \\
(50-68.5) \\
(62 / 104)\end{array}$ & $\begin{array}{c}27.6 \% \\
(23.8-31.7) \\
(135 / 489)\end{array}$ & $p<0.001$ \\
\hline & & & & & \\
\hline
\end{tabular}

This article is protected by copyright. All rights reserved 
Table 3: Comparison of baseline characteristics between patients from Communities $A, B$ and $C$ who accessed the outreach service

\begin{tabular}{|c|c|c|c|c|c|}
\hline \multicolumn{2}{|c|}{$n=124$} & \multicolumn{3}{|c|}{ Community } & \multirow[b]{2}{*}{$p$-value } \\
\hline Median (IQR) & All & A & B & C & \\
\hline Age (years) & $\begin{array}{c}48.6 \\
(40.9-57.2)\end{array}$ & $\begin{array}{c}46.0 \\
(43.6-54.1)\end{array}$ & $\begin{array}{c}49.2 \\
(41.3-57.5)\end{array}$ & $\begin{array}{c}48.7 \\
(38.1-58.4)\end{array}$ & 0.877 \\
\hline $\begin{array}{c}\text { Gender } \\
\text { (\% female) } \\
(95 \% \mathrm{Cl})(n)\end{array}$ & $\begin{array}{c}76.6 \\
(68.4-83.1) \\
(95 / 124)\end{array}$ & $\begin{array}{c}73.1 \\
(53.9-86.3) \\
(19 / 26)\end{array}$ & $\begin{array}{c}76.0 \\
(62.2-85.7) \\
(38 / 50)\end{array}$ & $\begin{array}{c}79.2 \\
(65.7-88.3) \\
(38 / 48)\end{array}$ & 0.832 \\
\hline $\begin{array}{c}\text { HbAlc } \\
(\mathrm{mmol} / \mathrm{mol})\end{array}$ & $\begin{array}{c}88 \\
(61-107)\end{array}$ & $\begin{array}{c}62 \\
(55-88)\end{array}$ & $\begin{array}{c}95 \\
(70-115)\end{array}$ & $\begin{array}{c}91 \\
(68-105)\end{array}$ & 0.010 \\
\hline SBP (mmHg) & $\begin{array}{c}120 \\
(110-137)\end{array}$ & $\begin{array}{c}120 \\
(110-136)\end{array}$ & $\begin{array}{c}120 \\
(110-138)\end{array}$ & $\begin{array}{c}123 \\
(113-136)\end{array}$ & 0.979 \\
\hline DBP ( & $\begin{array}{c}80 \\
(70-85)\end{array}$ & $\begin{array}{c}79 \\
(70-87)\end{array}$ & $\begin{array}{c}72 \\
(68-84)\end{array}$ & $\begin{array}{c}80 \\
(73-84)\end{array}$ & 0.266 \\
\hline $\begin{array}{l}\text { Urinary ACR } \\
(\mathrm{mg} / \mathrm{mmol})\end{array}$ & $\begin{array}{c}11.7 \\
(2.3-34.8)\end{array}$ & $\begin{array}{c}13.0 \\
(2.6-24.6)\end{array}$ & $\begin{array}{c}11.1 \\
(2.0-137.3)\end{array}$ & $\begin{array}{c}11.0 \\
(2.2-39.7)\end{array}$ & 0.910 \\
\hline $\begin{array}{l}\text { Total Cholesterol } \\
\text { (mmol/l) }\end{array}$ & $\begin{array}{c}4.3 \\
(3.8-5.0)\end{array}$ & $\begin{array}{c}4.2 \\
(3.6-4.5)\end{array}$ & $\begin{array}{c}4.4 \\
(3.9-4.9)\end{array}$ & $\begin{array}{c}4.4 \\
(3.8-5.1)\end{array}$ & 0.395 \\
\hline HDL-C & 0.9 & 1.00 & 0.80 & 0.9 & \\
\hline
\end{tabular}




\begin{tabular}{|cccccc|}
\hline (mmol/l) & $(0.80-1.00)$ & $(0.90-1.20)$ & $(0.70-0.93)$ & $(0.80-1.10)$ & 0.006 \\
LDL-C & 2.40 & 2.15 & 2.65 & 2.30 & \\
$\begin{array}{c}\text { (mmol/l) } \\
\text { (1.80-3.20) }\end{array}$ & $(1.70-2.95)$ & $(1.98-4.50)$ & $(1.80-3.20)$ & 0.290 \\
$\begin{array}{c}\text { Triglycerides } \\
\text { (mmol/l) }\end{array}$ & 2.50 & 2.10 & 2.95 & 2.10 & \\
& $(1.75-3.70)$ & $(1.40-3.40)$ & $(2.40-5.03)$ & $(1.80-3.10)$ & 0.008 \\
\hline
\end{tabular}

Glycosylated haemoglobin, HbA1c, systolic blood pressure, SBP, diastolic blood pressure, DBP, albumin:creatinine ratio, ACR, high density lipoprotein cholesterol, HDL-C, low density lipoprotein cholesterol, LDL-C 
Table 4: Comparison of clinical parameters at baseline and at 12-months for the 124 patients from Communities A, B and C who accessed the outreach service

\begin{tabular}{|c|c|c|c|}
\hline \multicolumn{4}{|l|}{$n=124$} \\
\hline Median (IQR) & Baseline & 12-months & $p$-value \\
\hline $\begin{array}{c}\text { HbA1c }) \\
(\mathrm{mmol} / \mathrm{mol})\end{array}$ & $\begin{array}{c}89 \\
(65-105)\end{array}$ & $\begin{array}{c}81 \\
(60-99)\end{array}$ & 0.002 \\
\hline SBP ( & $\begin{array}{c}120 \\
(110-137)\end{array}$ & $\begin{array}{c}120 \\
(112-140)\end{array}$ & $>0.05$ \\
\hline DBP (mmHg) & $\begin{array}{c}80 \\
(70-85)\end{array}$ & $\begin{array}{c}78 \\
(70-85)\end{array}$ & $>0.05$ \\
\hline $\begin{array}{l}\text { Urinary ACR } \\
\text { (mg/mmol) }\end{array}$ & $\begin{array}{c}11.7 \\
(2.3-34.8)\end{array}$ & $\begin{array}{c}9.0 \\
(2.3-62.1)\end{array}$ & $>0.05$ \\
\hline $\begin{array}{l}\text { Total Cholesterol } \\
\text { (mmol/l) }\end{array}$ & $\begin{array}{c}4.4 \\
(3.6-5.0)\end{array}$ & $\begin{array}{c}4.0 \\
(3.5-4.5)\end{array}$ & 0.038 \\
\hline $\begin{array}{c}\text { HDL-C } \\
(\mathrm{mmol} / \mathrm{l})\end{array}$ & $\begin{array}{c}0.9 \\
(0.8-1.0)\end{array}$ & $\begin{array}{c}0.9 \\
(0.8-1.1)\end{array}$ & $>0.05$ \\
\hline $\begin{array}{l}\text { LDL-C } \\
(\mathrm{mmol} / \mathrm{l})\end{array}$ & $\begin{array}{c}2.4 \\
(1.8-3.2)\end{array}$ & $\begin{array}{c}2.1 \\
(1.7-2.9)\end{array}$ & $>0.05$ \\
\hline $\begin{array}{l}\text { Triglycerides } \\
\text { (mmol/l) }\end{array}$ & $\begin{array}{c}2.5 \\
(1.8-3.7)\end{array}$ & $\begin{array}{c}2.1 \\
(1.5-3.3)\end{array}$ & $>0.05$ \\
\hline
\end{tabular}


Glycosylated haemoglobin, HbA1c, systolic blood pressure, SBP, diastolic blood pressure, DBP, albumin:creatinine ratio, ACR, high density lipoprotein cholesterol, HDL-C, low density lipoprotein cholesterol, LDL-C

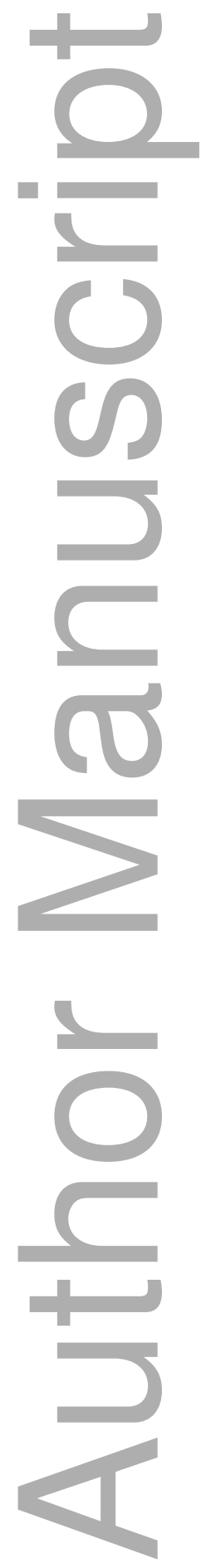

This article is protected by copyright. All rights reserved 


\section{University Library}

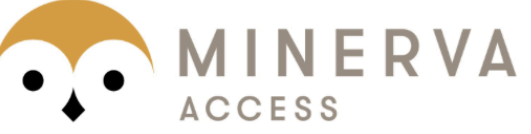

A gateway to Melbourne's research publications

Minerva Access is the Institutional Repository of The University of Melbourne

Author/s:

Hotu, C;Remond, M;Maguire, G;Ekinci, E;Cohen, N

Title:

Impact of an integrated diabetes service involving specialist outreach and primary health care on risk factors for micro- and macrovascular diabetes complications in remote Indigenous communities in Australia

Date:

2018-12-01

Citation:

Hotu, C., Remond, M., Maguire, G., Ekinci, E. \& Cohen, N. (2018). Impact of an integrated diabetes service involving specialist outreach and primary health care on risk factors for micro- and macrovascular diabetes complications in remote Indigenous communities in Australia. AUSTRALIAN JOURNAL OF RURAL HEALTH, 26 (6), pp.394-399. https:// doi.org/10.1111/ajr.12426.

Persistent Link:

http://hdl.handle.net/11343/284925 